Research Article

\title{
Centrosymmetric Binuclear Boron Compounds Derived from Dithiooxamides: Synthesis, Characterization, and Their Photophysical Properties
}

\author{
Marisol Ibarra-Rodríguez $\mathbb{D}^{1},{ }^{1}$ Blanca M. Muñoz-Flores, ${ }^{1}$ Jesús Lara Cerón, ${ }^{1}$ \\ Rosa Santillán, ${ }^{2}$ María E. Ochoa, ${ }^{2}$ Noemí Waksman, ${ }^{3}$ and Víctor M. Jiménez-Pérez $\mathbb{D}^{1}$ \\ ${ }^{1}$ Autonomous University of Nuevo Leon, Faculty of Chemical Sciences, University City, San Nicolás de los Garza, \\ 66451 Nuevo León, Mexico \\ ${ }^{2}$ Department of Chemistry, Center for Research and Advanced Studies of the IPN, A. P. 14-740, 07000 Mexico \\ City, Mexico \\ ${ }^{3}$ Autonomous University of Nuevo León, Faculty of Medicine, Francisco I. Madero and Dr. Eduardo Aguirre Pequeño, \\ Mitras Centro, 64460 Monterrey, Nuevo León, Mexico
}

Correspondence should be addressed to Víctor M. Jiménez-Pérez; victor.jimenezpr@uanl.edu.mx

Received 2 May 2018; Revised 26 June 2018; Accepted 29 July 2018; Published 4 October 2018

Academic Editor: Esteban P. Urriolabeitia

Copyright (C) 2018 Marisol Ibarra-Rodríguez et al. This is an open access article distributed under the Creative Commons Attribution License, which permits unrestricted use, distribution, and reproduction in any medium, provided the original work is properly cited.

\begin{abstract}
In this paper, we report the synthesis and characterization of new boron compounds derived from dithiooxamides. The compounds were characterized by NMR $\left({ }^{1} \mathrm{H}\right.$ and $\left.{ }^{13} \mathrm{C}\right)$, UV-vis, fluorescence spectroscopy, and high resolution mass spectrometry. The crystal structure of the mononuclear boron compound was determined by single-crystal X-ray diffraction analysis. The photophysical properties of the boron compounds were investigated, and we found moderate fluorescence emission (compound $2 \Phi_{\mathrm{F}}: 4.07 \%$ and compound $\left.4 \Phi_{\mathrm{F}}: 2.89 \%\right)$. We also observed that the mononuclear complex presented greater stability. Compound 4 showed interesting luminescent properties; in solid state, it exhibited an increase in fluorescence by mechanostimuli by changing to a bright red color, and also in solution, it showed a decrease in fluorescence intensity when oxygen and air were supplied to the solution.
\end{abstract}

\section{Introduction}

Boron compounds are important in biological systems, and they result from the interaction with hydroxyl and amine groups [1]. Boron has a high affinity for oxygen-forming borates that are involved in enzyme inhibition. The isoelectronic nature of $\mathrm{C}=\mathrm{C}$ and $\mathrm{B}-\mathrm{N}$ bonding increases the use of boron in organic synthesis [2]. Boron compounds are widely studied due to their various applications such as luminescent materials [3, 4], lasers [5-10], OLEDs [11-13], materials for nonlinear optics [14], and chemical materials used in fluorescent tests $[15,16]$, among others. The development of ladder-type $\pi$-conjugated molecules with fully ring-fused structures gives rise to a set of desired properties such as intense luminescence, good thermal stability, and high carrier mobility. These properties are important in terms of their applications in optoelectronics, organic fieldeffect transistors, and lasers [17-19]. Representative elements have been introduced to the $\pi$-conjugated skeleton to modulate the electronic structures and different properties like optical properties [20-26]. Some compounds have been reported with $\pi$-conjugated diboron ladders. Zhang and coworkers reported a series of ladder-type $\pi$-conjugated diboron complexes I-IV with high thermal stabilities (Figure 1) [27]. The same research group synthesized four novel diboron-containing $\pi$-conjugated ladders (V-VIII); skeletons were modified by introducing electron-withdrawing and electron-donating groups into different sites of the backbones. These materials present good thermal stability, high fluorescence quantum yields, and strong electron affinity [28]. Recently, Jacquemin and coworkers reported first-principle simulations of the excited states' properties of a large series of 


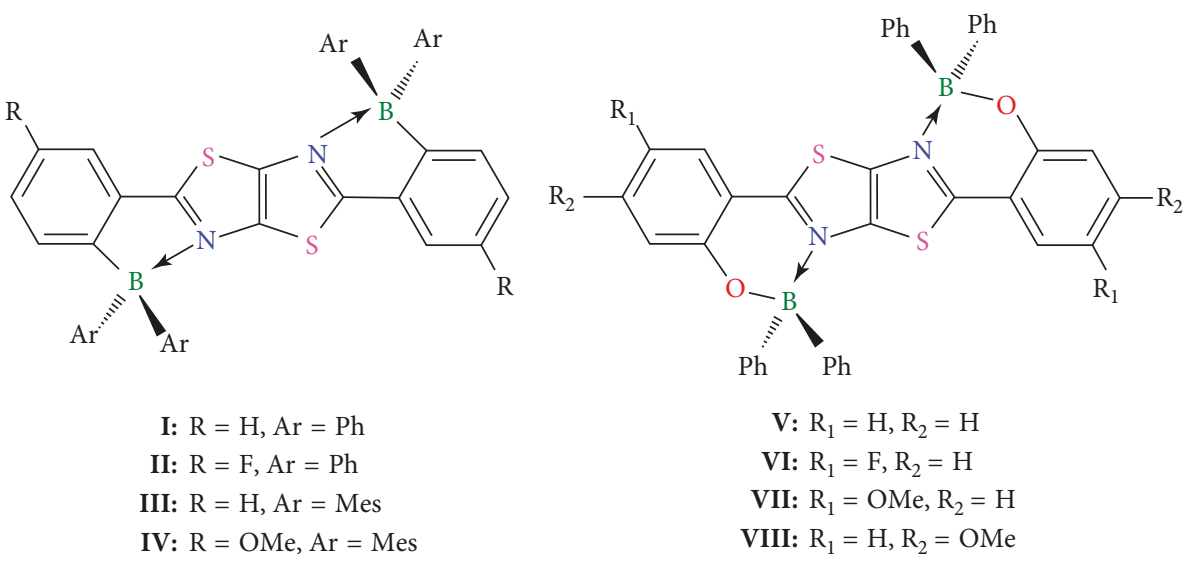

FIgURE 1: Diboron-containing ladder-type skeletons.

ladder-type $\pi$-conjugated organic molecules containing heteroatoms ( $\mathrm{Si}, \mathrm{S}, \mathrm{B}, \mathrm{O}$, and $\mathrm{N}$ ). They observed the phenyl rings that bonded to the boron atom do not play any role in the optical transition in compounds with similar core in this report [29]. Another research group has studied diboron BNheterocycles; they suggested that the location of BN units, the steric congestion, and the linker unit within the $\pi$-conjugated backbone can greatly affect the electronic structure of these molecules as well as their photophysical/photochemical properties [30]. It is therefore important to study the properties and characteristics of new compounds and to understand the impact when modifying the structures. Fluorescent sensors have received attention because they have advantages in terms of sensitivity, selectivity, and the easy detection of the fluorescence changes of the systems [31]. Due to this, we are interested in the synthesis of new materials with the ability to sense different stimuli. In the present work, we reported the synthesis and characterization of two new boron compounds derived from dithiooxamides. They present greater stability in the solid state than in solution; however compound 2 was unstable in solution, obtaining an X-ray structure for a mononuclear species.

\section{Experimental Methods}

2.1. Material and Equipment. All starting materials were purchased from the Aldrich Chemical Company. Solvents were used without further purification. Melting points were performed on an Electrothermal Mel-Temp apparatus and were uncorrected. A high-resolution mass spectrum was obtained by LC/MSD TOF, on an Agilent Technologies instrument, with APCI as the ionization source. UV-vis spectra were obtained with a PerkinElmer Lambda 356 UV/VIS spectrophotometer, and emission measurements were performed on a Fluorolog-3 spectrofluorometer. ${ }^{1} \mathrm{H}$ and ${ }^{13} \mathrm{C}$ spectra were recorded on a Bruker avance DPX 400. Chemical shifts (ppm) were relative to $\left(\mathrm{CH}_{3}\right)_{4} \mathrm{Si}$ for ${ }^{1} \mathrm{H}$ and ${ }^{13} \mathrm{C}$.

2.2. Crystal Structure Determination. The crystal data of 2a were recorded on an Enraf-Nonius Kappa-CCD ( $\lambda$ MoKa $=0.71073 \AA$, graphite monochromator, $T=293$
K-CCD rotating images scan mode). The crystal was mounted on a Lindeman tube. The structures were solved by direct methods using SHELXS-97 [32] and refined against $F^{2}$ on all data by full-matrix least-squares with SHELXL-97 [33]. All of the software manipulations were done under the WIN-GX environment program set [34]. All heavier atoms were found by Fourier map difference and refined anisotropically. Some hydrogen atoms were found by Fourier map differences and refined isotropically. The remaining hydrogen atoms were geometrically modelled and are not refined. Crystallographic data for the structures reported in this paper have been deposited in the Cambridge Crystallographic Data Centre: CCDC 1817739 for 2a.

2.3. Synthesis of 6,6'-(Thiazolo[5,4-d]thiazole-2,5-diyl)bis (2,4-di-tert-butylphenol) (1). A solution of ethanebis(thioamide) $0.24 \mathrm{~g} \quad(2 \mathrm{mmol})$ and 3,5-di-tert-butyl-2hydroxybenzaldehyde $0.936 \mathrm{~g}(4 \mathrm{mmol})$ in $4 \mathrm{ml}$ of DMF were heated under reflux for $24 \mathrm{~h}$. The reaction mixture slowly cooled to room temperature; the precipitated solid was filtered and washed with methanol and acetone, giving a yellow solid ( $0.13 \mathrm{~g}-12 \%$ yield). The compound was soluble in THF. M. P.: $364^{\circ} \mathrm{C} .{ }^{1} \mathrm{H}$ NMR $\left(400 \mathrm{MHz}, \mathrm{CDCl}_{3}, 298 \mathrm{~K}\right)$ $\delta=1.30(\mathrm{~s}, 18 \mathrm{H}, t-\mathrm{Bu}-6), 1.42(\mathrm{~s}, 18 \mathrm{H}, t-\mathrm{Bu}-8), 7.37[\mathrm{~d}, 2 \mathrm{H}$, $\mathrm{H} 7], 7.39$ (d, 2H, H9), and $11.83(\mathrm{~s}, 2 \mathrm{H}, \mathrm{OH}) .{ }^{13} \mathrm{C}$ NMR $\left(100 \mathrm{MHz}, \mathrm{CDCl}_{3}, 298 \mathrm{~K}\right) \delta=170.99$ (C3), 152.99 (C5), 140.59 (C8), 137.25 (C6), 126.9 (C7, C9), 119.86 (C4), 28.47 $\left(\mathrm{CH}_{3}, t\right.$-Bu-6), $30.40\left(\mathrm{CH}_{3}, t \mathrm{Bu}-8\right), 33.3(\mathrm{C}, t-\mathrm{Bu}-6), 34.36(\mathrm{C}$, $t$-Bu-8). APCI-TOF-M.S. in positive ion mode calc. for $\left[\left(\mathrm{C}_{32} \mathrm{H}_{42} \mathrm{~N}_{2} \mathrm{O}_{2} \mathrm{~S}_{2}+\mathrm{H}\right)^{+}\right]$: 551.276049 u.m.a; Exp.: 551.275297.

2.4. Synthesis of 2,5-Bis(3,5-di-tert-butyl-2-((difluoroboryl) oxy)phenyl)thiazolo[5,4-d] thiazole (2). A solution of 6,6'(thiazolo[5,4- $d$ ] thiazole-2,5-diyl)bis(2,4-di-tert-butylphenol) $0.27 \mathrm{~g}(0.5 \mathrm{mmol})$ in $30 \mathrm{ml}$ of THF and $1 \mathrm{ml}$ of $\mathrm{Et}_{2} \mathrm{O} \cdot \mathrm{BF}_{3}$ was added and heated under reflux for $24 \mathrm{~h}$. The reaction mixture slowly cooled to room temperature; the precipitated solid was filtered and washed with hexane, giving a yellow solid ( $0.22 \mathrm{~g}, 68 \%$ yield). The compound was soluble in THF. M. P.: $354-358^{\circ} \mathrm{C}$. APCI-TOF-M.S. in positive ion mode calc. 


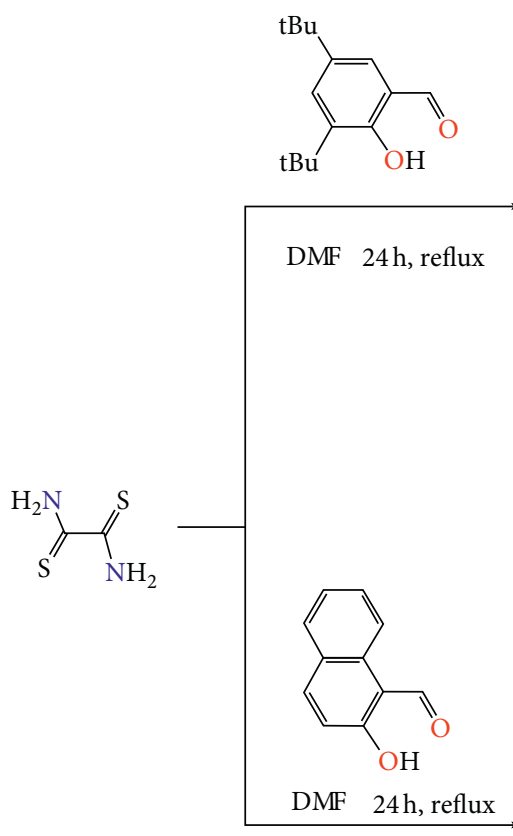

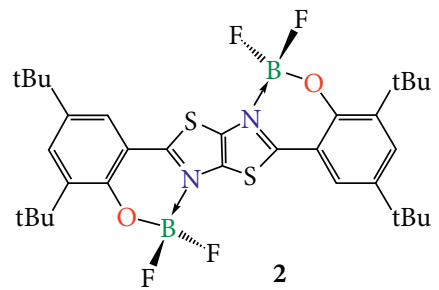<smiles></smiles>

$2 a$
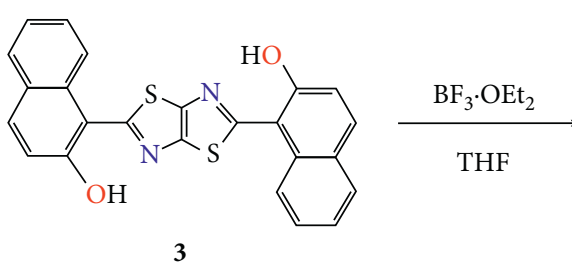

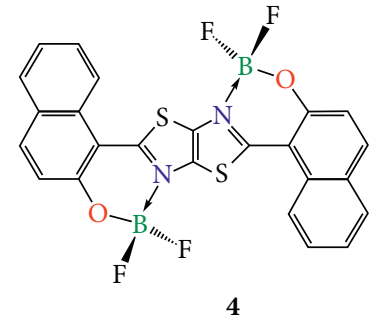

Scheme 1: Synthesis of boron compounds 1-4.

for $\left[\left(\mathrm{C}_{32} \mathrm{H}_{40} \mathrm{~B}_{2} \mathrm{~F}_{4} \mathrm{~N}_{2} \mathrm{O}_{2} \mathrm{~S}_{2}-1 \mathrm{~F}\right)^{+}\right]: \quad 627.26694$ u.m.a; $\quad$ Exp.: 627.266647. UV-vis (THF): $\lambda_{\text {abs/max }} 436 \mathrm{~nm}$.

2.5. Synthesis of 1,1'-(Thiazolo[5,4-d]thiazole-2,5-diyl)bis (naphthalen-2-ol) (3). A solution of ethanebis(thioamide)

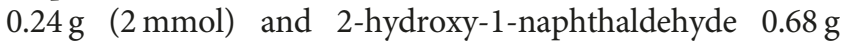
$(4 \mathrm{mmol})$ in $4 \mathrm{ml}$ of DMF were heated under reflux for $24 \mathrm{~h}$. The reaction mixture slowly cooled to room temperature; the precipitated solid was filtered and washed with methanol, giving a red solid (0.34 g-39.7\% yield). The compound was soluble in THF. M. P.: $339^{\circ} \mathrm{C} .{ }^{1} \mathrm{H}$ NMR (400 MHz, DMSO- $d_{6}$, $298 \mathrm{~K}) \delta=7.38$ (m, 4H, H6 and H10), 7.56 (t, 2H, H11), 7.91 (d, 2H, H9), 8.02 (d, 2H, H7), 8.49 (d, 2H, H12), 11.08 (s, 2H, $\mathrm{OH}) .{ }^{13} \mathrm{C}$ NMR $\left(100 \mathrm{MHz}, \mathrm{DMSO}-d_{6}, 298 \mathrm{~K}\right) \delta=113.04(\mathrm{C} 4)$, 118.58 (C6), 123.95 (C10), 124.71 (C12), 128.23 (C11), 128.83 (C9), 132.80 (C7), 150.53 (C8), 155.05 (C5), 164.39 (C3). $\operatorname{COSY}\left[\delta_{\mathrm{H}} / \delta_{\mathrm{C}}\right]: 8.48 / 7.53(\mathrm{H} 12 / \mathrm{H} 11), 7.94 / 7.40(\mathrm{H} 9 / \mathrm{H} 10)$, 7.35/8.01 (H6/H7). HETCOR $\left[\delta_{\mathrm{H}} / \delta_{\mathrm{C}}\right]: \quad 7.37 / 118.49$ (H6/C6), 7.41/123.92 (H10/C10), 7.53/128.19 (H11/C11), 7.92/128.70 (H9/C9), 8.00/132.88 (H7/C7), 8.48/124.69 (H12/C12). APCI-TOF-M.S. in positive ion mode calc. for $\left[\left(\mathrm{C}_{24} \mathrm{H}_{14} \mathrm{~N}_{2} \mathrm{O}_{2} \mathrm{~S}_{2}+\mathrm{H}\right)^{+}\right]$: 427.056947 u.m.a; Exp.: 427.05174.

2.6. Synthesis of 2,5-Bis(2-((difluoroboryl)oxy)naphthalen1-yl)thiazolo[5,4-d]thiazole (4). A solution of 1,1'-(thiazolo [5,4-d] thiazole-2,5-diyl)bis(naphthalen-2-ol) $\quad 0.27 \mathrm{~g}$ $(0.5 \mathrm{mmol})$ in $30 \mathrm{ml}$ of THF, $0.5 \mathrm{ml}$ of $\mathrm{Et}_{2} \mathrm{O} \cdot \mathrm{BF}_{3}$ was added and were heated under reflux for $24 \mathrm{~h}$. The reaction mixture slowly cooled to room temperature, the precipitated solid was filtered and washed with hexane; giving a red solid $(0.19 \mathrm{~g}-72.79 \%$ yield $)$. The compound was soluble in DMSO and THF. Yield of $0.19 \mathrm{~g}(72.79 \%)$. M. P.: $340^{\circ} \mathrm{C} .{ }^{1} \mathrm{H}$ NMR $\left(400 \mathrm{MHz}, \mathrm{DMSO}-d_{6}, 298 \mathrm{~K}\right) \delta=7.36(\mathrm{~m}, 4 \mathrm{H}, \mathrm{H} 6$ y H10), 7.54 (t, 2H, H11), 7.91 (d, 2H, H9), 7.99 (d, 2H, H7), 8.46 (d, 2H, H12). ${ }^{13} \mathrm{C}$ NMR (100 MHz, DMSO- $\left.d_{6}, 298 \mathrm{~K}\right)$ $\delta=112.96$ (C4), 118.68 (C6), 123.89 (C10), 124.69 (C12), 128.21 (C11), 128.83 (C9), 132.19 (C7), 150.50 (C8), 155.13 (C5), 164.27 (C3). APCI-TOF-M.S. in positive ion mode calc. for $\left[\left(\mathrm{C}_{24} \mathrm{H}_{12} \mathrm{~B}_{2} \mathrm{~F}_{4} \mathrm{~N}_{2} \mathrm{O}_{2} \mathrm{~S}_{2}+\mathrm{H}\right)^{+}\right]$: 523.05407 u.m.a; Exp.: 523.421632. UV-vis (THF): $\lambda_{\mathrm{abs} / \max } 428 \mathrm{~nm}$.

2.7. Absorbance, Emission, and Luminescence Quantum Yields. UV-vis absorption spectra were measured on a PerkinElmer Lambda 365 spectrophotometer (a solution of $1 \mathrm{mg}$ of the compound in $50 \mathrm{ml}$ of solvent was prepared to determine the photophysical properties). Optical band gap $(\mathrm{Eg})$ was determined from the intercept with the $\mathrm{X}$ axis of the tangent of the absorption spectrum drawn at absorbance of 0.1 [35]. The emission spectra have been recorded with a Fluorolog-3 spectrofluorometer, by exciting $10 \mathrm{~nm}$ below the longer wavelength absorption band. The molar extinction coefficients were calculated by the rearranged Beer-Lambert equation. Fluorescence quantum yields in solution were determined according to the procedure reported in literature $[36,37]$ and using quinine sulphate in $\mathrm{H}_{2} \mathrm{SO}_{4} 0.1 \mathrm{M}$ as the standard (quinine sulphate 


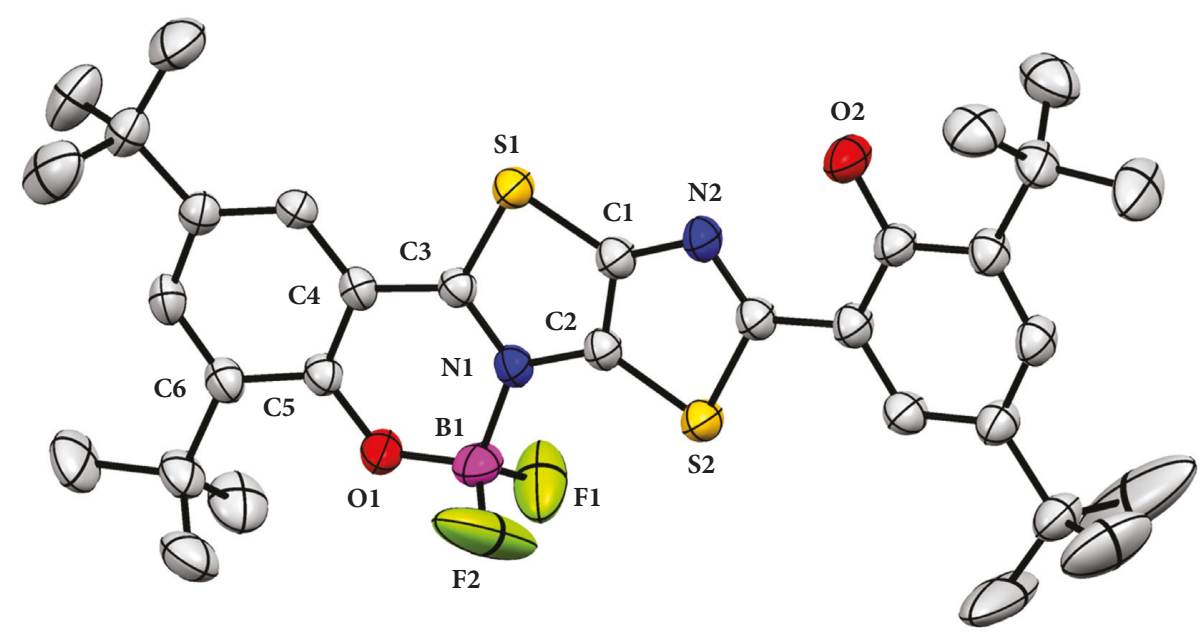

Figure 2: Structure of 2a. Ellipsoids are drawn at the 50\% probability level.

$\lambda_{\text {ext }}=365 \mathrm{~nm}, \Phi=0.546$ at room temperature) [38]. Three solutions with absorbance at the excitation wavelength lower than 0.1 were analyzed for each sample, and the quantum yield was averaged.

\section{Results and Discussion}

3.1. Synthesis. The ligands (1 and 3) were synthesized by condensation reactions of two equivalents of aldehyde with dithiooxamide in DMF under reflux for $24 \mathrm{~h}$, according to the procedure previously reported $[39,40]$. They were fully characterized by NMR $\left({ }^{1} \mathrm{H}\right.$ and $\left.{ }^{13} \mathrm{C}\right), \mathrm{UV}$-vis, and mass spectrometry. The boron compounds were obtained in moderate yields $(60-73 \%)$ by excess of $\mathrm{Et}_{2} \mathrm{O} \cdot \mathrm{BF}_{3}$ with the ligand under reflux in THF (Scheme 1). The resulting boron compounds are soluble in organic solvents compounds like THF and DMSO. The compounds were characterized by NMR $\left({ }^{1} \mathrm{H}\right.$ and $\left.{ }^{13} \mathrm{C}\right)$, UV-vis, and mass spectrometry. The binuclear compound 2 is unstable in solution; we tried to obtain crystals suitable for X-ray diffraction but only crystallize the complex with one boron atom. The compound $2 \mathbf{a}$ crystallized by slow evaporation of THF/hexane (1/9). Suitable single crystals for X-ray analysis were obtained, and their ORTEP drawing of molecular structure is shown in Figure 2, while refinement parameters are available in Table 1.

The complex mononuclear 2 a crystallized in the $\mathrm{P} 2_{(1)} / n$ space group, the molecules were monoclinic and crystallized as a yellow prism. The crystal structure of $\mathbf{2 a}$ shows the one boron atom tetracoordinated with the ligand and the formation of four heterocycles of five and six members. Boron atoms adopt typical tetrahedral geometry, bond lengths B-O 1.418(5) $\AA$ and B-N 1.582(4) $\AA$ which are characteristic for tetracoordinated boron complex, compared with molecules reported $[41,42]$. The crystal has a rigid $\pi$-conjugated between the rings 2,3 , and 4 ; however, the ring 5 is slightly outside of the plane of the thiazolothiazole skeleton caused by the steric effect of the substituent groups tert-butyl (Figure 3). The structure of the compound shows intermolecular interactions with S2 and the proton of the tert-
TABLe 1: Crystal data of compound 2a.

\begin{tabular}{|c|c|}
\hline Empirical formula & $\mathrm{C}_{32} \mathrm{H}_{38} \mathrm{BF}_{2} \mathrm{~N}_{2} \mathrm{O}_{2} \mathrm{~S}_{2}$ \\
\hline Formula weight & 595.57 \\
\hline Crystal size $\left(\mathrm{mm}^{3}\right)$ & $0.38 \times 0.24 \times 0.20$ \\
\hline Crystal system & Monoclinic \\
\hline Space group & $\mathrm{P} 21 / n$ \\
\hline$a,(\AA ⿻)$ & $15.2111(19)$ \\
\hline$b,(\AA)$ & $11.1385(15)$ \\
\hline$c,(\AA)$ & $20.455(3)$ \\
\hline$A,\left(^{\circ}\right)$ & 90 \\
\hline $\mathrm{B},\left(^{\circ}\right)$ & $111.597(7)$ \\
\hline$\gamma,\left(^{\circ}\right)$ & 90 \\
\hline$V,\left(\AA^{3}\right)$ & $3222.3(7)$ \\
\hline$Z$ & 4 \\
\hline$\rho($ calc $)\left(\mathrm{mg} / \mathrm{m}^{3}\right)$ & 1.228 \\
\hline$\mu\left(\mathrm{mm}^{-1}\right)$ & 0.207 \\
\hline F000 & 1260 \\
\hline Index ranges & $-18 \leq h \geq 18,-13 \leq k \geq 13,-24 \leq l \geq 23$ \\
\hline $2 \theta\left({ }^{\circ}\right)$ & $2.33-24.84$ \\
\hline Temperature, $(\mathrm{K})$ & $296(2)$ \\
\hline Reflns. collected & 39617 \\
\hline Reflns. indep & 5708 \\
\hline Refl. observed $(4 \sigma)$ & 4001 \\
\hline$R$ (int) & 0.0828 \\
\hline Goodness of fit & 1.026 \\
\hline $\mathrm{R} 1, \mathrm{wR} 2(I>2 \sigma(I))$ & $0.0614 / 0.1425$ \\
\hline R1, wR2 (all data) & $0.0956 / 0.1597$ \\
\hline
\end{tabular}

butyl group of other molecules (2.923-2.995 $\AA$ ) and parallelly displaced $\pi-\pi$ interactions in the range from 3.905 to $4.111 \AA$. The intramolecular interactions shown are (H15-S2, 2.616), (N2-H of $\mathrm{OH}, 1.931)$, ( $\mathrm{H} 13$ of $t \mathrm{Bu}-\mathrm{O} 2,2.336-2.278)$, (S1-H9, 2.741), and (H6 of $t \mathrm{Bu}-\mathrm{O} 1,2.380-2.314) \AA$ (Figure 4).

Distances: $\mathrm{B}(1)-\mathrm{O}(1)$ 1.418(5), O(1)-C(5) 1.341(4), B(1)$\mathrm{N}(1)$ 1.582(4), B(1)-F(1) 1.324(6), B(1)-F(2) 1.370(5), N(1)-C (2) $1.375(4), \mathrm{C}(2)-\mathrm{C}(1)$ 1.356(4), C(1)-S(1) 1.726(4), S(1)-C (3) $1.731(3), C(1)-\mathrm{N}(2) 1.361(4)$, and $\mathrm{C}(2)-\mathrm{S}(2) 1.706(4) \AA$. Bond angles: $\mathrm{F}(1)-\mathrm{B}(1)-\mathrm{N}(1)$ 107.5(3), F(2)-B(1)-O(1) 110.1 (3), $\mathrm{F}(2)-\mathrm{B}(1)-\mathrm{N}(1)$ 105.8(3), and $\mathrm{N}(1)-\mathrm{B}(1)-\mathrm{O}(1) 109.5(3)^{\circ}$. 


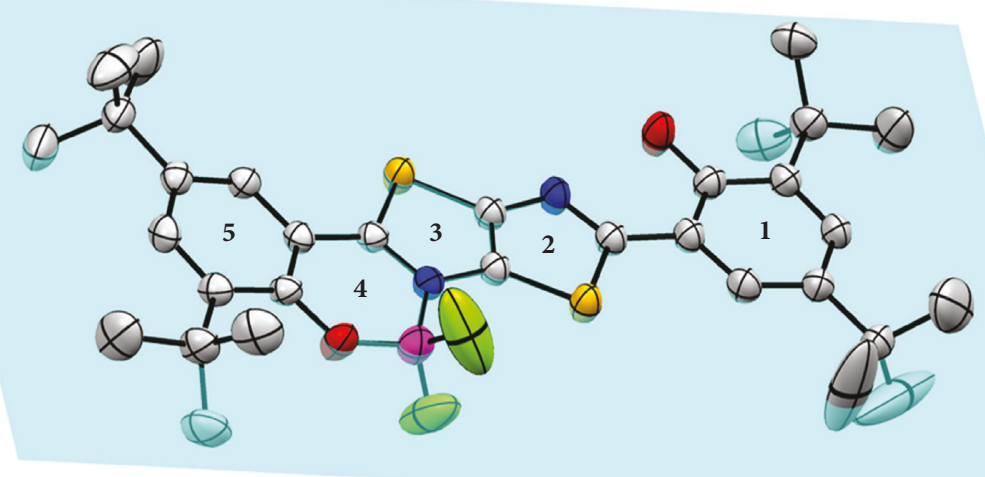

Figure 3: Plane of structure of compound 2a.

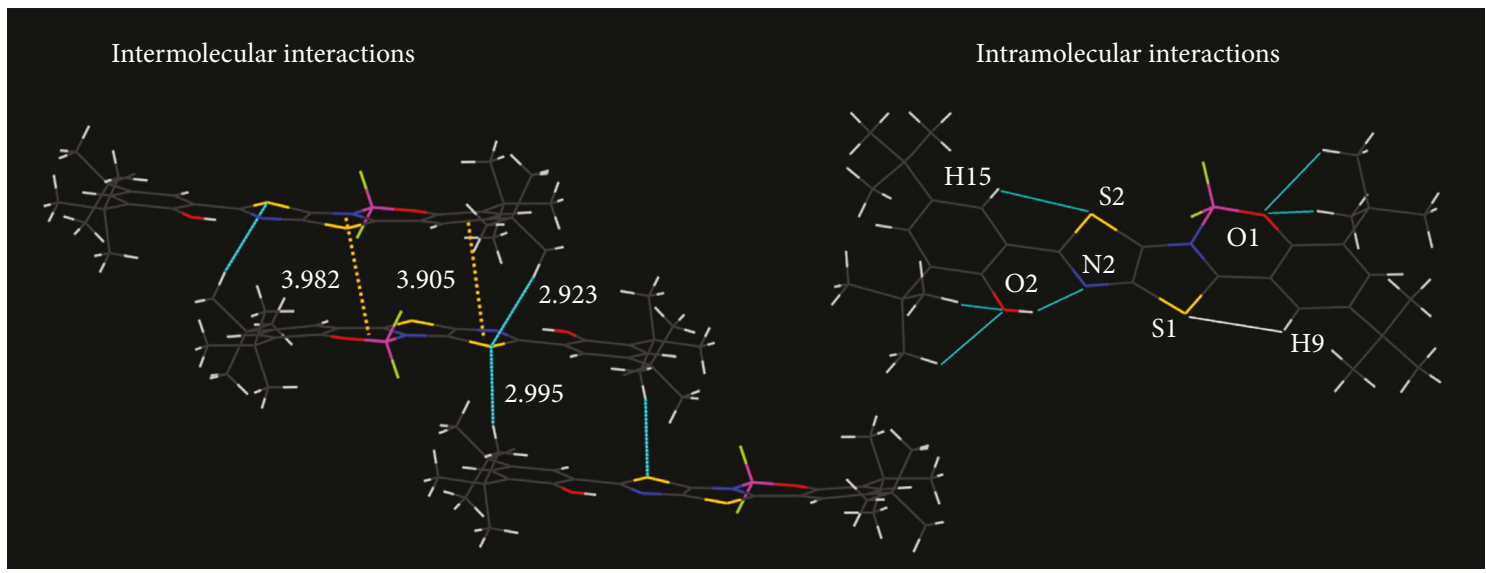

FIGURE 4: Intermolecular and intramolecular interactions of compound 2a (H15-S2, 2.616), (N2-H of OH, 1.931), (H13 of (t) Bu-O2, 2.336-2.278), (S1-H9, 2.741), (H6 of (t) Bu-O1, 2.380-2.314) ̊..

$2 a$

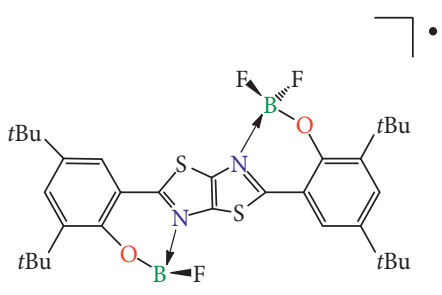

$627.266394 \mathrm{~m} / z(39.3 \%)$

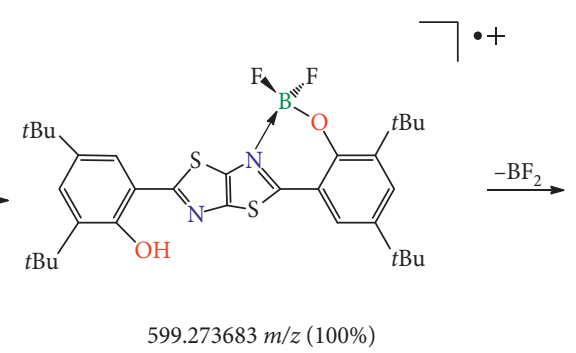

1

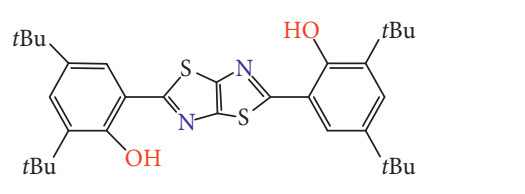

$551.275199 \mathrm{~m} / \mathrm{z}(8.9 \%)$

Scheme 2: Proposed fragmentation pattern of dimeric boron compound 2.

3.2. Solution and Solid Structures. The spectra ${ }^{1} \mathrm{H}$ NMR for the ligands (1) and (3) show the downfield H-bonded phenolic proton at 11.83 and $11.08 \mathrm{ppm}$; when the boron atom is coordinated, this signal disappears and gives the first indication for the formation of compound 4. For complex $\mathbf{2}$, it was difficult to obtain a clean spectrum (Figure S4); it shows a mixture of signals between the ligand (1) and the possible compound 2 , which gives us a possible indication of instability. The proposed structure of the boron compounds was confirmed by the mass spectra of boron derivatives; it showed the base peak corresponding to the molecular ion. The compound $\mathbf{2}$ shows a pattern of fragmentation due to the loss of one boron atom, obtaining the mononuclear compound (2a), followed by the loss of the second boron atom to obtain the ligand (Scheme 2). The isotopic distribution of parent ions in the spectra demonstrated the presence of two atoms of boron in the compound 2. The comparison of the predicted theoretical and experimental isotopic distributions of spectra for the compound is given in Figure 5. However, compound 4 does not present the 
+TOF MS: 0.200 to $0.218 \mathrm{~min}$ from J-281016-89-01.wiff Agllent subtracted (1.104 to $1.316 \mathrm{~min}$ )

Max. $4.6 \mathrm{e} 4$ counts

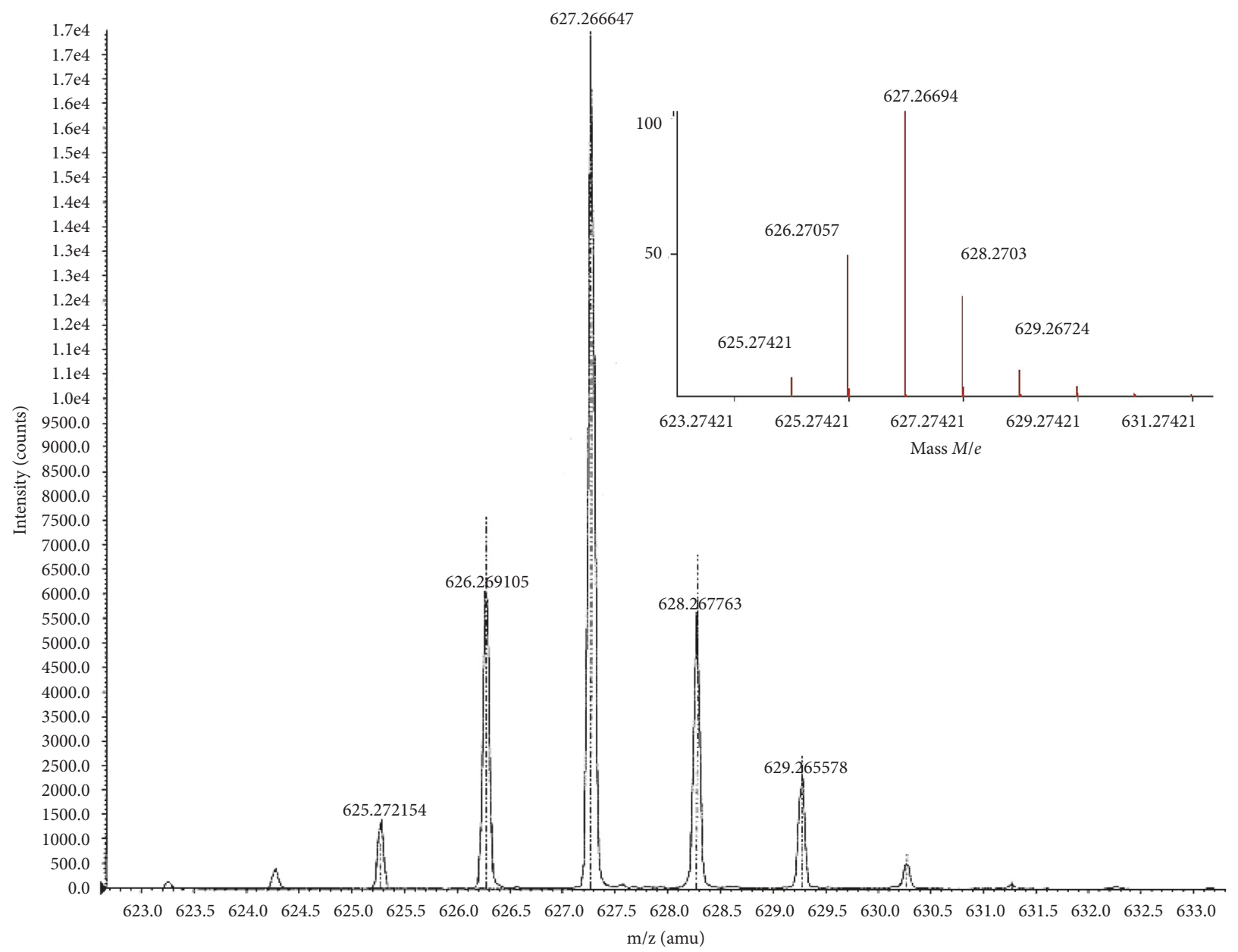

Figure 5: Comparison of theoretical and experimental isotopic distributions of spectra of the $[\mathrm{M}-\mathrm{F}]^{+}$of compound 2 . The spectra clearly indicate the presence of two boron atoms.

fragmentation pattern corresponding to the species [MBF2]; mainly, the ligand 3 fragment is observed (427.0677 m/z, 15.8\%) (Figure S11).

3.3. Photophysical Characterization. The boron complexes are more emissive in the solid state than in solution. The UV-vis absorption and emission spectra of $\mathbf{2}$ and $\mathbf{4}$ in THF are shown in Figure 6 and the date in Table 2. Interestingly, the absorption spectra of complex 2 show an intense peak at $436 \mathrm{~nm}$. The first absorptions are mostly attributed to the transitions from HOMO to LUMO, excited states involve possibly, mainly, the $\pi$-conjugated core [29]. The fluorescence spectra show maximum wavelengths between 465 and $509 \mathrm{~nm}$ for the compound 4 is more intense the emission. Compound 4 in solution (solvent THF) absorbs at $428 \mathrm{~nm}$ and emits at $509 \mathrm{~nm}$; however in the solid state, it shows a clear red color, this difference in color is due to the fact that the compound in solution shows solvatochromism $[43,44]$. The molar extinction coefficients $(\varepsilon)$ of $\mathbf{2}$ and $\mathbf{4}$ were in the range of $51,000-56,000 \mathrm{M}^{-1} \cdot \mathrm{cm}^{-1}$. These values $(\varepsilon)$ were higher than compounds with the same central cores reported recently [27, 30]. This behavior was possibly caused by the introduction of the fluorine atoms at the boron atom, similar to that reported by Matsui research group, they studied pyrazine-boron complexes with lower molar extinction coefficient values of $(\varepsilon)$ lower when the boron atom presents substituents as in comparison with phenyl substituents [45]. However, the molar extinction coefficients $(\varepsilon)$ of $\mathbf{2}$ and $\mathbf{4}$ were less than the binuclear species with different central cores [46]. The optical band gap values $(2.75-2.80 \mathrm{eV})$ are slightly lower than similar compounds reported by Wang[30]. Fluorescence quantum yields in solution were determined according to the procedure reported in literature [36, 37], the boron compound exhibits lower values of fluorescence quantum yields of 2.9 to 4.1 than similar compounds reported as V-VIII [28], these low values of $\Phi_{F}$ can be due to the presence of electro-attractor atoms like fluorine and the promotion of nonradiative processes, and this behavior is similar to that reported by Kubota et al. [47]. Compound 2 shows a gradual decomposition in THF because it shows a slightly orange coloration, and 


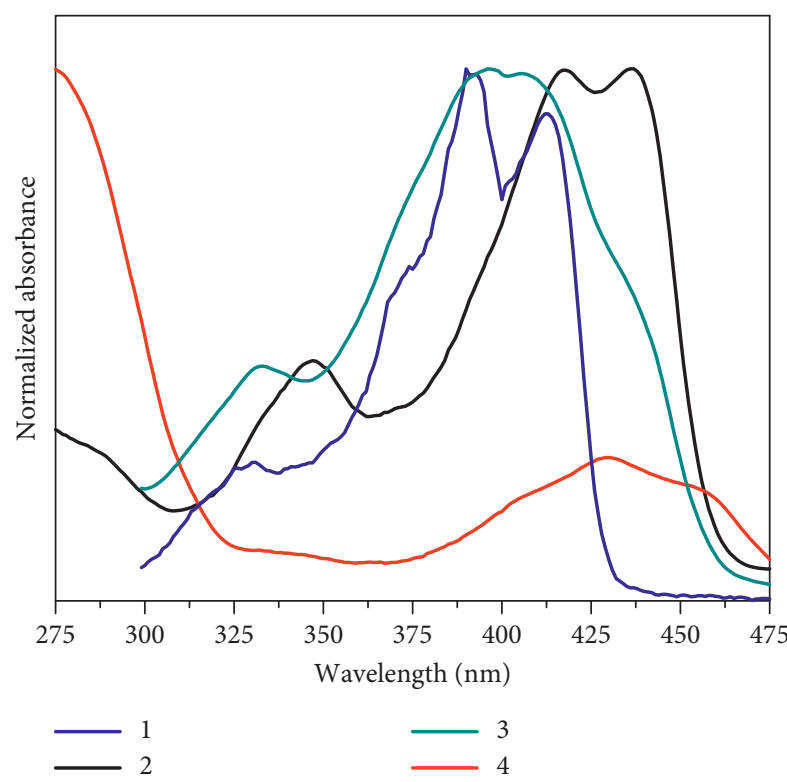

(a)

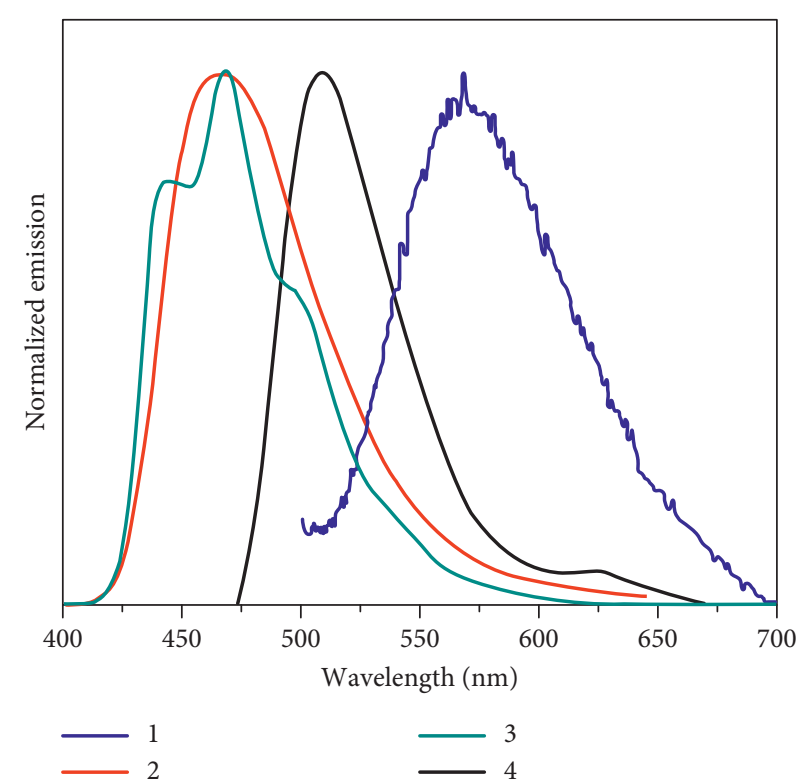

(b)

FIgURe 6: Absorption and emission spectrum of compounds 1-4 in THF.

TABLE 2: Photophysical data of compounds in THF.

\begin{tabular}{lccccccc}
\hline Comp & $\lambda_{\mathrm{abs}}(\mathrm{nm})$ & $\varepsilon * 10^{4}\left(\mathrm{M}^{-1} \cdot \mathrm{cm}^{-1}\right)$ & $\operatorname{Eg}(\mathrm{eV})$ & $\lambda_{\text {ext }}(\mathrm{nm})$ & $\lambda_{\text {em }}(\mathrm{nm})$ & $\Delta \nu\left(\mathrm{cm}^{-1}\right)$ & $\Phi_{\mathrm{F}}(\%)$ \\
\hline $\mathbf{1}$ & 412 & 4.3 & 2.87 & 402 & 570 & 6728 \\
$\mathbf{2}$ & 436 & 5.6 & 2.75 & 426 & 465 & 1430 \\
$\mathbf{3}$ & 407 & 4.2 & 2.67 & 397 & 468 & 3.67 \\
$\mathbf{4}$ & 428 & 5.1 & 2.80 & 418 & 509 & 3203 \\
\hline
\end{tabular}

$\lambda_{\text {abs: }}$ absorption (maximum); $\varepsilon$ : molar extinction coefficients (for two samples measured three times, and then an average of these data was made); $\varepsilon * 10^{4}=$ molar extinction coefficients multiplied to $10^{4}$; Eg: optical band gaps; $\lambda_{\text {ext }}$ : excitation; $\lambda_{\text {em }}$ : emission (maximum), correspond to those used for calculation of quantum yield; $\Delta v$ : Stoke's shift; $\Phi_{\mathrm{F}}$ : fluorescence quantum yield.

after being exposed for one day at room temperature, the color of the solution changes to light yellow similar to the ligand; in addition, the absorption spectra of the solution at room temperature for one day is similar to the ligand (Figure S12).

The compounds present greater luminescence in the solid state and, as a result of this, they were ground for two minutes on a mortar. It is important to mention the boron compounds respond to mechanical stimuli such as friction observing. Compound $\mathbf{2}$ decreases the fluorescence intensity, similar to other molecules [48], while compound $\mathbf{4}$ slightly changes its coloration taking a bright red color (Figure 7); this may indicate a slight change in molecular arrangements by the application of the force [49].

It is important to study the ability to sense oxygen in cells because the deficit and excess oxygen is associated with health problems or diseases [50, 51]. Recently, a boron compound with the ability to sense oxygen at the cellular level has been reported [52]. Therefore, the effect of dissolved oxygen concentration on the emission intensity of compound 4 was evaluated in the degassed THF at 25 bar and with oxygen pressure for $60 \mathrm{~s}$, followed by the addition of air for $60 \mathrm{~s}$ in two cycles (Figure 8). In the first cycle, the compound 4 shows a decrease in the fluorescence intensity, and in the second cycle a slight shift towards the blue is observed. When applying air in the second cycle, the compound decreases even more than the intensity of emission, the behavior similar to that reported in the literature, a consequence of paramagnetic behavior of oxygen molecules as well as generating the triplet state [53]. However, compound 4 in the presence of nitrogen for 60 seconds exhibited an increase in the emission, which may be a consequence of oxidation of the compound, and due to absorption spectra, the compound shows a hypsochromic shift.

\section{Conclusions}

In summary, we describe the synthesis, characterization in solution, and the solid state of two boron compounds, observing greater stability in the solid state; it was possible to obtain a structure of $\mathrm{x}$-rays for a mononuclear compound. The effect of oxygen and dissolved air in compound 4 was studied observing a decrease in the intensity of emission upon addition of oxygen and increase in this emission when it is substituted by nitrogen, and in the 

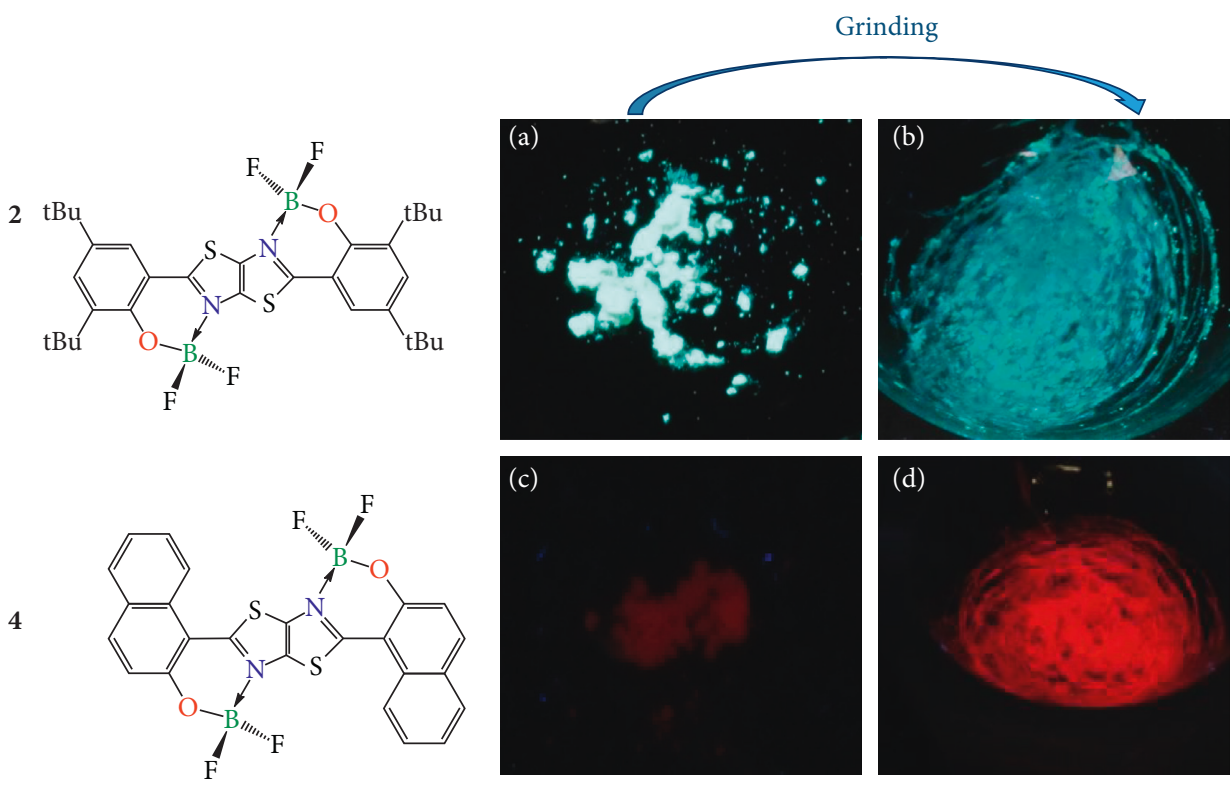

Figure 7: Fluorescence images of compounds 2 and 4. (a, c) Under UV light at $25^{\circ} \mathrm{C}$. (b, d) After grinding under UV light at $25^{\circ} \mathrm{C}$.

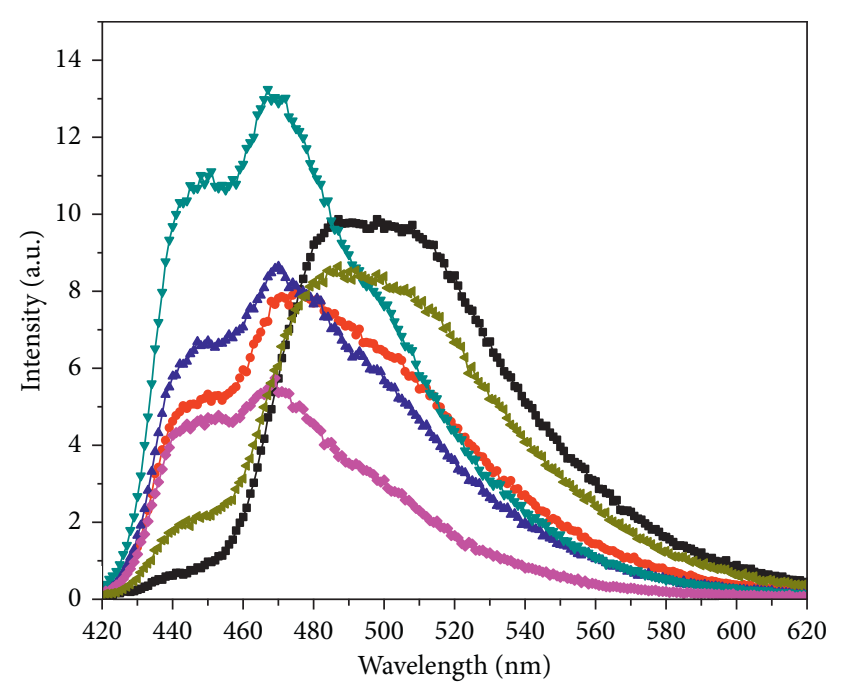

$$
\begin{array}{ll}
\text { First cycle } & \text { Second cycle } \\
\rightarrow \text { Degassed } & \rightarrow \mathrm{O}_{2} 120 \mathrm{~s} \\
\leftarrow \mathrm{O}_{2} 60 \mathrm{~s} & \rightarrow-\text { Air } 120 \mathrm{~s} \\
\rightarrow \text { Air } 60 \mathrm{~s} & \rightarrow \mathrm{N}_{2} 60 \mathrm{~s}
\end{array}
$$

FIGURE 8: Emission spectra of compound 4 in THF degassed with oxygen, air, and nitrogen.

solid state, this binuclear exhibited a slight mechanochromism in response to mechanical grinding; this behavior can be attributed to changes in the molecular arrangements.

\section{Data Availability}

The data used to support the findings of this study are available from the corresponding author upon request.

\section{Conflicts of Interest}

The authors declare that they have no conflicts of interest.

\section{Acknowledgments}

This research was financially supported by CONACYT (grant 240011). MIR thanks CONACYT for providing scholarship.

\section{Supplementary Materials}

The supplementary materials contain NMR spectra and mass spectra for 1-4 (Figures S1-S12), a graphical abstract (Figure S13), and X-ray crystallographic data of 2a (Figure S14). (Supplementary Materials)

\section{References}

[1] W. Yang, X. Gao, and B. Wang, "Boronic acid compounds as potential pharmaceutical agents," Medicinal Research Reviews, vol. 23, no. 3, pp. 346-368, 2003.

[2] H. C. Brown, S. V. Malhotra, and P. V. Ramachandran, "Organoboranes for synthesis 17. Generality of hydroboration-amination for the conversion of terpenes into enantiomerically pure terpenylamines their utility for gas chromatographic analysis of chiral carboxylic acids," Tetrahedron: Asymmetry, vol. 7, no. 12, pp. 3527-3534, 1996.

[3] Z. Guoqing, L. Jiwei, and L. Cassandra, "Mechanochromic luminescence quenching: force-enhanced singlet-to-triplet intersystem crossing for iodide-substituted difluoroborondibenzoylmethane-dodecane in the solid state," Inorganic Chemistry, vol. 49, no. 23, pp. 10747-10749, 2010.

[4] Z. Guoqing, L. Jiwei, S. Michal, and L. Cassandra, "Polymorphism and reversible mechanochromic luminescence for solid-state difluoroboron avobenzone," Journal of the 
American Chemical Society, vol. 132, no. 7, pp. 2160-2162, 2010.

[5] S. Wang, "Luminescence and electroluminescence of $\mathrm{Al}(\mathrm{III})$, $\mathrm{B}(\mathrm{III}), \mathrm{Be}(\mathrm{II})$ and $\mathrm{Zn}(\mathrm{II})$ complexes with nitrogen donors," Coordination Chemistry Reviews, vol. 215, no. 1, pp. 79-98, 2001.

[6] S. Anderson, M. S. Weaver, and A. J. Hudson, "Materials for organic electroluminescence: aluminium vs. boron," Synthetic Metals, vol. 111-112, pp. 459-463, 2000.

[7] Y. Li, W. Bu, J. Guo, and Y. Wang, "A mixed pyridine-phenol boron complex as an organic electroluminescent material," Chemical Communications, vol. 16, pp. 1551-1552, 2000.

[8] J. Zyss, Molecular Nonlinear Optics: Materials, Physics and Devices, Academic Press, San Diego, CA, USA, 1st edition, 1994.

[9] R. W. Boyd, Nonlinear Optics, Academic Press, San Diego, CA, USA, 1st edition, 1992.

[10] G. Beer, J. Daub, and K. Rurack, "Chiral discrimination with a fluorescent boron dipyrromethene," Chemical Communications, vol. 12, pp. 1138-1139, 2001.

[11] H. Chen, Y. Chi, C. S. Liu et al., "Rational color tuning and luminescent properties of functionalized boron containing 2pyridyl pyrrolide complexes," Advanced Functional Materials, vol. 15, no. 4, pp. 567-574, 2005.

[12] Y. Cui, Q. Liu, D. R. Bai, J. Wen-Li, Y. Tao, and S. Wang, "Organoboron compounds with an 8-hydroxyquinolato chelate and its derivatives: substituent effects on structures and luminescence," Inorganic Chemistry, vol. 44, no. 3, pp. 601-609, 2005.

[13] H. Zhang, H. Cheng, Y. Kaigi, Z. Peng, T. Wenjing, and Y. Wang, "Synthesis, structures, and luminescent properties of phenol-pyridyl boron complexes," Inorganic Chemistry, vol. 45, no. 7, pp. 2788-2794, 2006.

[14] M. Rodríguez, G. Ramos, M. L. Alcalá et al., "One-pot synthesis and characterization of novel boronates for the growth of single crystals with nonlinear optical properties," Dyes and Pigments, vol. 87, no. 1, pp. 76-83, 2010.

[15] J. Shao, H. Guo, S. Ji, and J. Zhao, "Styryl-BODIPY based redemitting fluorescent OFF-ON molecular probe for specific detection of cysteine," Biosensors and Bioelectronics, vol. 26, no. 6, pp. 3012-3017, 2011.

[16] T. Tachikawa, N. Wang, S. Yamashita, S.-C. Cui, and T. Majima, "Design of a highly sensitive fluorescent probe for interfacial electron transfer on a $\mathrm{TiO}_{2}$ surface," Angewandte Chemie International Edition, vol. 49, no. 46, pp. 8593-8597, 2010.

[17] A. Craft, A. C. Grimsdale, and A. B. Holmes, "Electroluminescent conjugated polymers-seeing polymers in a new light," Angewandte Chemie International Edition, vol. 37, no. 4, pp. 402-428, 1998.

[18] M. D. Watson, A. Fechtenk€otter, and K. M€ullen, "Big is beautiful-"aromaticity" revisited from the viewpoint of macromolecular and supramolecular benzene chemistry," Chemical Reviews, vol. 101, no. 5, pp. 1267-1300, 2001.

[19] J. E. Anthony, "The larger acenes: versatile organic semiconductors," Angewandte Chemie International Edition, vol. 47, no. 3, pp. 452-483, 2008.

[20] S. Yamaguchi, C. Xu, and K. Tamao, "Bis-silicon-bridged stilbene homologues synthesized by new intramolecular reductive double cyclization," Journal of the American Chemical Society, vol. 125, no. 45, pp. 13662-13663, 2003.

[21] C. Xu, A. Wakamiya, and S. Yamaguchi, "Ladder oligo(pphenylenevinylene)s with silicon and carbon bridges," Journal of the American Chemical Society, vol. 127, no. 6, pp. 1638-1639, 2005.
[22] C. Xu, A. Wakamiya, and S. Yamaguchi, "General silaindene synthesis based on intramolecular reductive cyclization toward new fluorescent silicon-containing $\pi$-electron materials," Organic Letters, vol. 6, no. 21, pp. 3707-3710, 2004.

[23] T. Okamoto, K. Kudoh, A. Wakamiya, and S. Yamaguchi, "General synthesis of extended fused oligothiophenes consisting of an even number of thiophene rings," Chemistry- $A$ European Journal, vol. 13, no. 2, pp. 548-556, 2007.

[24] A. Fukazawa, M. Hara, T. Okamoto et al., "Bis-phosphorylbridged stilbenes synthesized by an intramolecular cascade cyclization," Organic Letters, vol. 10, no. 5, pp. 913-916, 2008.

[25] T. Agou, J. Kobayashi, and T. Kawashima, "Development of a general route to periphery-functionalized azaborines and ladder-type azaborines by using common intermediates," Chemical Communications, no. 30, pp. 3204-3206, 2007.

[26] J. Bouchard, S. Wakim, and M. Leclerc, "Synthesis of diindolocarbazoles by cadogan reaction: route to ladder oligo (paniline)s," Journal of Organic Chemistry, vol. 69, no. 17, pp. 5705-5711, 2004.

[27] D. Li, Z. Zhang, S. Zhao, Y. Wang, and H. Zhang, "Diboroncontaining fluorophores with extended ladder-type $\pi$-conjugated skeletons," Dalton Transactions, vol. 40, no. 6 , pp. 1279-1285, 2011.

[28] D. Li, Y. Yuan, H. Bi et al., "Boron-bridged $\pi$-conjugated ladders as efficient electron-transporting emitters," Inorganic Chemistry, vol. 50, no. 11, pp. 4825-4831, 2011.

[29] S. Chibani, D. Laurent, B. Le Guennic, and D. Jacquemin, "Excited states of ladder-type $\pi$-conjugated dyes with a joint SOS-CIS(D) and PCM-TD-DFT approach," Journal of Physical Chemistry A, vol. 119, no. 21, pp. 5417-5425, 2015.

[30] D. Yang, Y. Shi, T. Peng, and S. Wang, "BN-heterocycles bearing two $\mathrm{BN}$ units: influence of the linker and the location of BN units on electronic properties and photoreactivity," Organometallics, vol. 36, no. 14, pp. 2654-2660, 2017.

[31] W. Xu-dong, S. Xin-hong, H. Chun-yan, J. Y. Chaoyong, C. Guonan, and C. Xi, "Preparation of reversible colorimetric temperature nanosensors and their application in quantitative two-dimensional thermo-imaging," Analytical Chemistry, vol. 83, no. 7, pp. 2434-2437, 2011.

[32] G. M. Sheldrick, "Phase annealing in SHELX-90: direct methods for larger structures," Acta Crystallographica Section A Foundations of Crystallography, vol. 46, no. 6, pp. 467-473, 1990.

[33] G. M. Sheldrick, SHELX-97: Program for the Solution and Refinement of Crystal Structures, Universität Göttingen: Göttingen, Göttingen, Germany, 1997.

[34] L. J. Farrugia, "WinGXsuite for small-molecule single-crystal crystallography," Journal of Applied Crystallography, vol. 32, no. 4, pp. 837-838, 1999.

[35] P. Kale, A. C. Gangal, R. Edla, and P. Sharma, "Investigation of hydrogen storage behavior of silicon nanoparticles," International Journal of Hydrogen Energy, vol. 37, no. 4, pp. 3741-3747, 2011.

[36] A. T. R. Williams, S. A. Winfield, and J. N. Miller, "Relative fluorescence quantum yields using a computer-controlled luminescence spectrometer," Analyst, vol. 108, no. 1290, pp. 1067-1071, 1983.

[37] K. Ye, J. Wang, H. Sun et al., "Supramolecular structures and assembly and luminescent properties of quinacridone derivatives," Journal of Physical Chemistry B, vol. 109, no. 16, pp. 8008-8016, 2004.

[38] W. H. Melhuish, "Quantum efficiencies of fluorescence of organic substances: effect of solvent and concentration of the 
fluorescent solute," Journal of Physical Chemistry, vol. 65, no. 2, pp. 229-235, 1961.

[39] D. A. Thomas, "Derivatives of thiazolo[5,4-d] thiazole," Journal of Heterocyclic Chemistry, vol. 7, no. 2, pp. 457-462, 1970.

[40] C. Knighton, J. Hallett, M. Kariuki, and J. A. Pope, “A onestep synthesis towards new ligands based on arylfunctionalised thiazolo[5,4-d]thiazole chromophores," Tetrahedron Letters, vol. 51, no. 41, pp. 5419-5422, 2010.

[41] D. Li, Y. Yuan, H. Bi et al., "Boron-bridged $\pi$-conjugated ladders as efficient electron-transporting emitters," Inorganic Chemistry, vol. 50, no. 11, pp. 4825-4831, 2011.

[42] F. Kaiser, M. White, and A. Hutton, "Enantioselective preparation of a stable boronate complex stereogenic only at boron," Journal of the American Chemical Society, vol. 130, no. 49 , pp. 16450-16451, 2008.

[43] C. Reus and T. Baumgartner, "Stimuli-responsive chromism in organophosphorus chemistry," Dalton Transactions, vol. 45, no. 5, pp. 1850-1855, 2016.

[44] I. A. Karpenko, Y. Niko, V. P. Yakubovskyi et al., "Push-pull dioxaborine as fluorescent molecular rotor: far-red fluorogenic probe for ligand-receptor interactions," Journal of Materials Chemistry C, vol. 4, no. 14, pp. 3002-3009, 2016.

[45] Y. Kubota, H. Hara, S. Tanaka, K. Funabiki, and M. Matsui, "Synthesis and fluorescence properties of novel pyrazine boron complexes bearing a $\beta$-iminoketone ligand," Organic Letters, vol. 13, no. 24, pp. 6544-6547, 2011.

[46] Y. Kubota, Y. Ozaki, K. Funabiki, and M. Matsui, "Synthesis and fluorescence properties of pyrimidine mono- and bisboron complexes," Journal of Organic Chemistry, vol. 78, no. 14, pp. 7058-7067, 2013.

[47] Y. Kubota, S. Tanaka, K. Funabiki, and M. Matsui, "Synthesis and fluorescence properties of thiazole-boron complexes bearing a $\beta$-ketoiminate ligand," Organic Letters, vol. 14, no. 17, pp. 4682-4685, 2012.

[48] T. Seki, Y. Takamatsu, and H. Ito, “A screening approach for the discovery of mechanochromic gold(I) isocyanide complexes with crystal-to-crystal phase Transitions," Journal of the American Chemical Society, vol. 138, no. 19, pp. 6252-6260, 2016.

[49] K. Ohno, S. Yamaguchi, A. Nagasawa, and T. Fujihara, "Mechanochromism in the luminescence of novel cyclometalated platinum(II) complexes with a-aminocarboxylates," Dalton Transactions, vol. 45, no. 13, pp. 5492-5503, 2016.

[50] E. Roussakis, Z. Li, A. J. Nichols, and C. L. Evans, "Oxygensensing methods in biomedicine from the macroscale to the microscale," Angewandte Chemie International Edition, vol. 54, no. 29, pp. 8340-8362, 2015.

[51] S. Schreml, R. M. Szeimies, L. Prantl, S. Karrer, M. Landthaler, and P. Babilas, "Oxygen in acute and chronic wound healing," British Journal of Dermatology, vol. 163, no. 2, pp. 257-268, 2010.

[52] C. A. De Rosa, S. A. Seaman, A. S. Mathew et al., "Oxygen sensing difluoroboron $\beta$-diketonate polylactide materials with tunable dynamic ranges for wound imaging," ACS Sensors, vol. 1, no. 11, pp. 1366-1373, 2016.

[53] C. Schweitzer and R. Schmidt, "Physical mechanisms of generation and deactivation of singlet oxygen," Chemical Reviews, vol. 103, no. 5, pp. 1685-1758, 2003. 

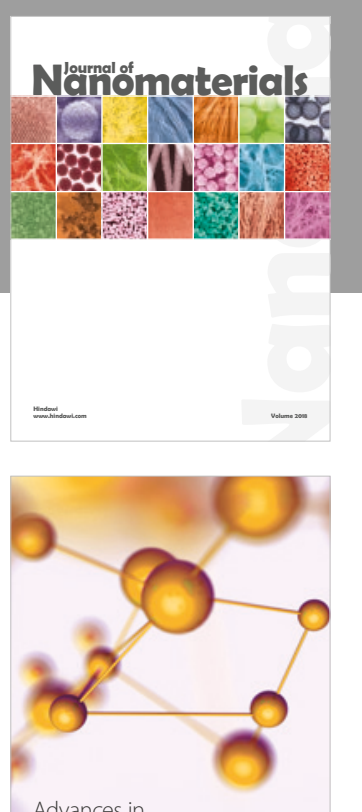

Physical Chemistry
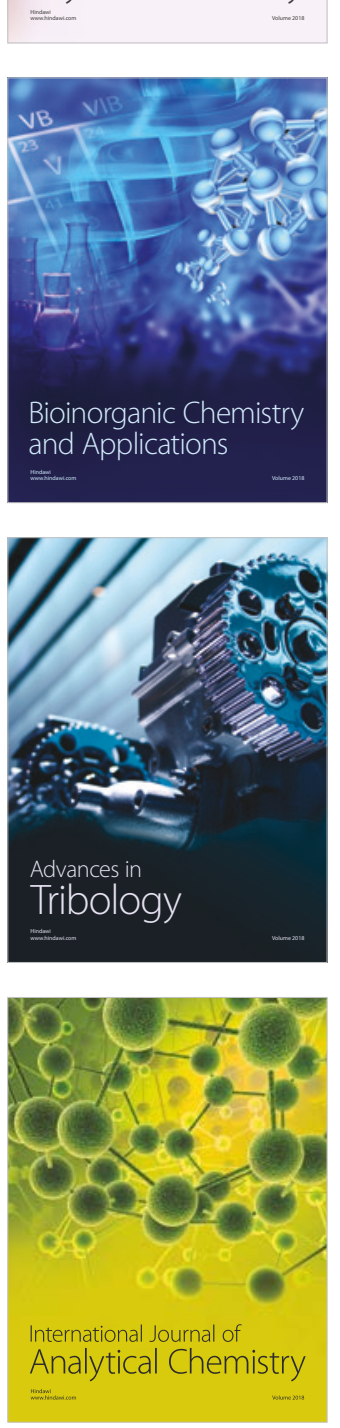

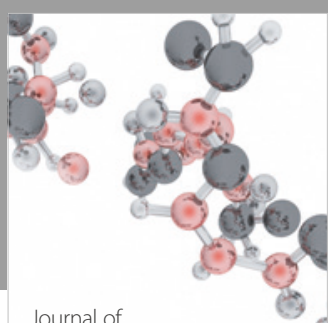

Analytical Methods

in Chemistry

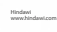

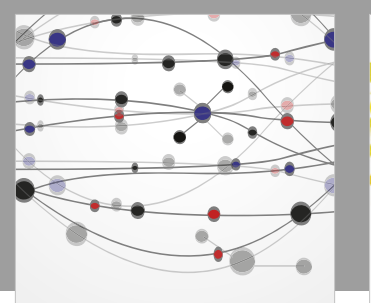

The Scientific World Journal

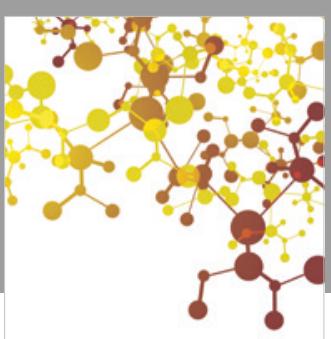

Journal of

Applied Chemistry
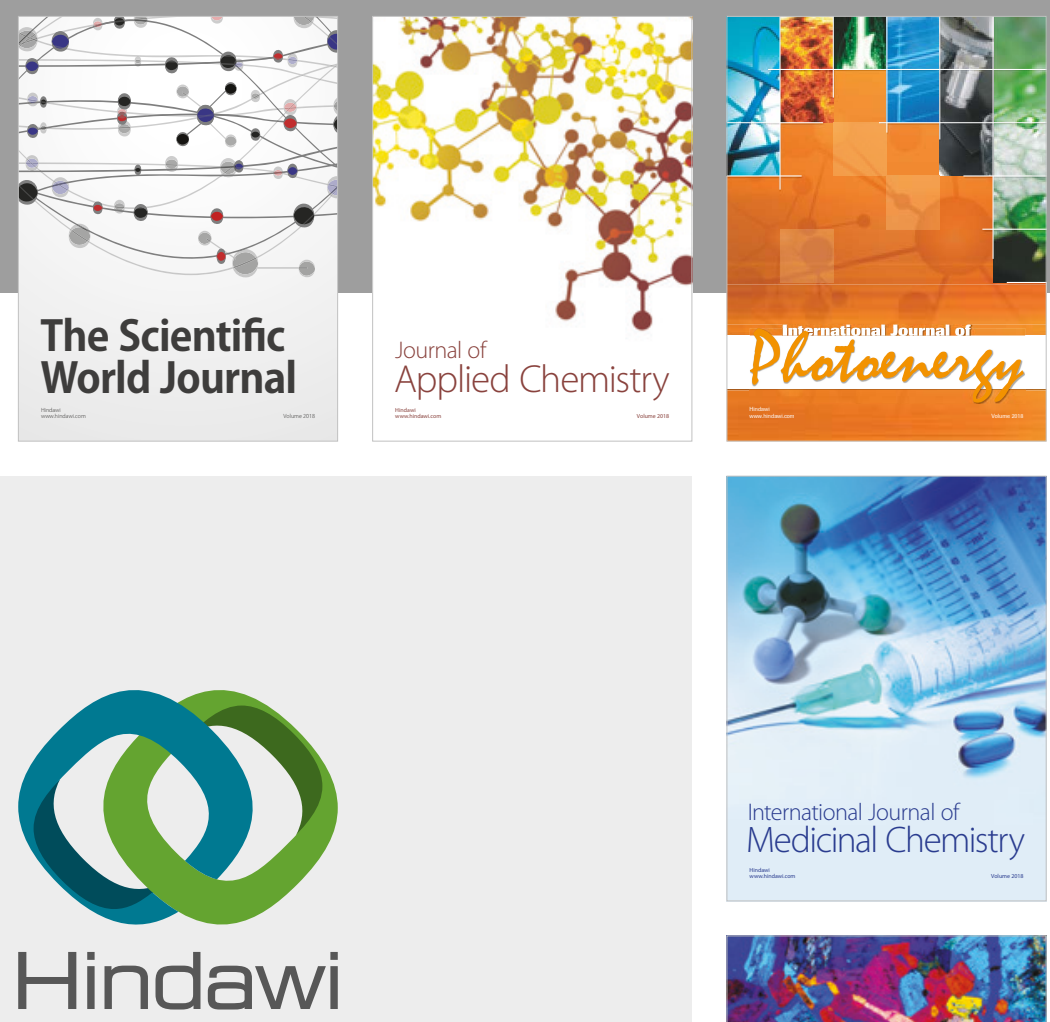

Submit your manuscripts at

www.hindawi.com
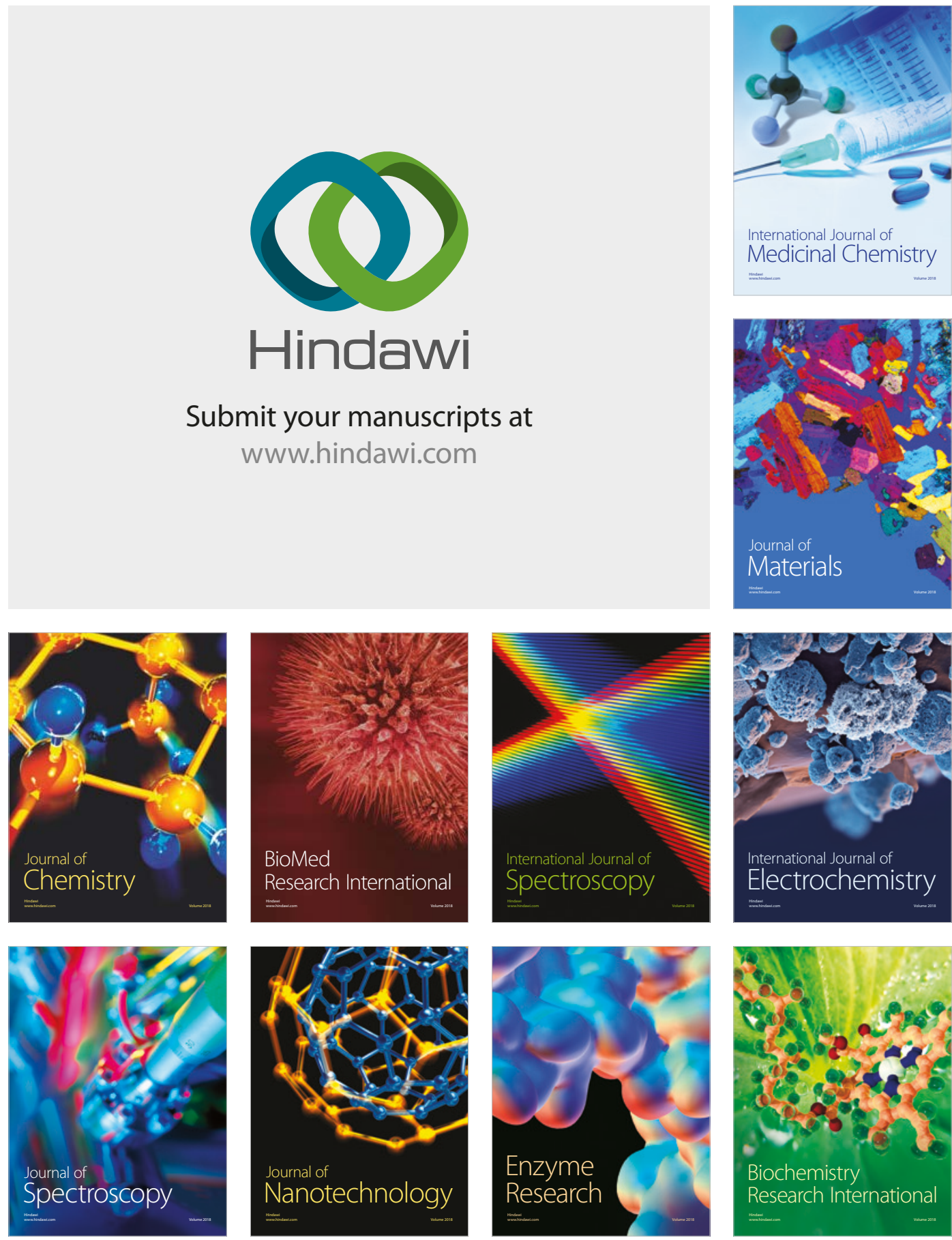
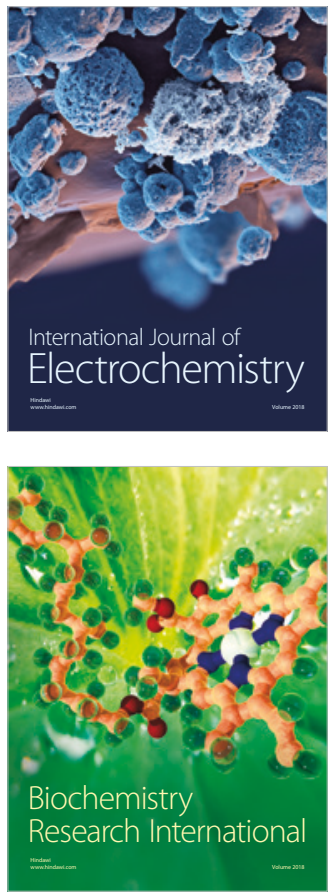